Diese verschiedenen Kohlenwasserstoffe wurden durch Brom condensirt und aus der Bromverbindung in reinem Zustande dadurch erhalten, dass man diese in luftleeren Röhren auf $250^{\circ}$ mit metallischem Kupfer, Wasser und Jodkalium erhitzte. Hierdurch konnten Propylen und das ölbildende Gas leicht aus ihren Bromverbindungen wieder hergestellt werden. Lässt man dabei das Kupfer weg, so erhält man die entsprechende Hydrüre, aus dem gebromten ölbildenden Gase den Kohlenwasserstoff $\mathrm{C}^{4} \mathrm{H}^{6}$, aus dem Propylenbromür den Kohlenwasserstoff $\mathrm{C}^{6} \mathrm{H}^{8}$. Diese Methode der umgekehrten Substitution ist eine allgemein anwendbare. Der hiermit gegebene Zusammenhang zwischen den Kohlenwasserstoffen und den Alkoholen einerseits und der der Alkohole mit anderen organischen Körpern, macht es zu einer ausgemachten Sache, dass eine ganze Menge organischer Körper aus den Elementen zusammengesetzt werden können. (L'Institut 1856. - ('hem. Centrbl. 1856. No. 45.) B.

\title{
Ueber zwei neue Zuckerarten.
}

W. Johnson erhielt von Wm. P. Blake zwei von ibm gesammelte Zucker mit folgender Notiz.

Den einen Zucker sammeln die Indianer von Tefou in Californien von der Oberfläche der Blätter einer Rohrart, die sehr reichlich an den Ufern der Flüsse und an niedrigen nassen Plätzen wächst. Man schneidet das Rohr, legt es auf Häute, die auf dem Boden ausgebreitet werden und sammelt dann den Zucker, den man mit den Bruchstücken der Blätter, mit denen man ihn erhält, zusammen in Kuchen formt, die in neu gebundene Matten von Tulé, d. h. dicht zusammengebundene runde Binsen, eingepackt werden.' Dieser Zucker heisst Panoche und wird von den Indianern selhr geschätzt. Auch die Eingewanderten benutzen ihn zum Süssmachen des Kaffees. Die Farbe dieses Zuckers ist weiss oder grau, mit einem Schein ins Grüne. Er ist nicht körnig oder krystallinisch, sondern mehr einer eingedickten Melasse ähnlich. Er schmeckt süss und zugleich salzig, wie wenn ihm Kochsalz beigemengt wäre. Ausser Blätterstïcken findet man eine grosse Anzahl der grünen Fliege (Aphis) darin. Blake ist der Meinung, dass dieses Insekt den' Zucker fabricire, eine Ansicht, die er später dadurch bestätigt fand, dass er grosse Mengen dieses Insekts auf den Blät- 
tern jenes Rohres sah, die durch die Excremente derselben ganz und gar überzogen waren.

Die zweite Zuckerart heisst Pine-sugar, weil sie von einer Fichte abstammt, die in Menge in der Sierra $\mathrm{Ne}$ vada wächst.

Johnson erhielt den ersten Zucker nicht mehr fest, er hatte so viel Wasser angezogen, dass das Papier, worin er eingepackt war, ganz davon durchdrungen war. Er zog ihn nit Wasser aus und reinigte ihn. Zum Krystallisiren konnte er nicht gebraucht werden. $\mathrm{Er}$ verhält sich $\mathrm{zu}$ Reagentien wie ein Gemenge von Rohr- und Traubenzucker, und hinterlässt auf der Zunge einen unangenehmen bitteren Geschmack.

Der Fichtenzucker hatte das Ansehen von rundlichen Knollen von 0,5 Zoll Durchmesser, ist völlig löslich in Wasser und siedendem Alkohol. Diese Zuckerart ist ohne Zweifel dieselbe, die Berthelot schon als Pinit beschrieben hat, und eine von Johnson angestellte Analyse stimmt mit den von Berthelot erhaltenen analytischen Resultaten ziemlich überein. (Sillim. d'amer. $J$. 2. Sér. Bd.22. - Chem. Centrbl. 1856. No.48.) B.

\section{Veber einige neue Verbindungen des Cadmiums.}

v. Hauer hat eine zweite Verbindung der Chlorsalze von Cadmium und Nickel dargestellt, die in die erste Gruppe der von v. Hau er aufgestellten Chlorcadmiumverbindungen gehört, nämlich:

Das Doppelsalz, $2 \mathrm{NiCl}+\mathrm{CdCl}+12 \mathrm{HO}$ ein in grossen dunkelgrünen, rhombischen, kurzen Säulen krystallisirendes Salz von besonderer Schönheit. Man erhält es leicht, wenn man die beiden Componenten in den der Formel entsprechenden Verhältnissen zusammenbringt und die Lösung freiwillig verdunsten lässt. Die Analyse ist:

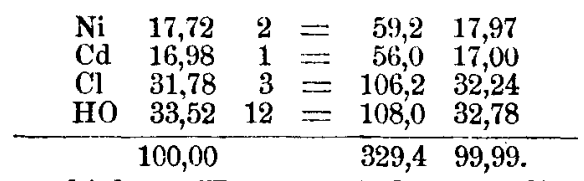

Ferner erhielt v. Hauer, indem er die wässerigen Lösungen von Brombaryum und Bromeadmium freiwillig verdunsten liess:

Das Brombaryum-Bromcadmium, $\mathrm{Ba} \mathrm{Br}+\mathrm{Cd} \mathrm{Br}+$ $4 \mathrm{HO}$, in grossen, farblosen, glänzenden Krystallen von 